Article

\title{
Detection of Anomalies and Changes of Rainfall in the Yellow River Basin, China, through Two Graphical Methods
}

\author{
Hao Wu ${ }^{1,2}$, Xinyan $\mathrm{Li}^{1,2}$ and Hui Qian ${ }^{1,2, *}$ \\ 1 School of Environmental Science and Engineering, Chang'an University, Xi'an 710054, China; \\ wuhao@chd.edu.cn (H.W.); lixinyan@chd.edu.cn (X.L.) \\ 2 Key Laboratory of Subsurface Hydrology and Ecological Effect in Arid Region of Ministry of Education, \\ Chang'an University, Xi'an 710054, China \\ * Correspondence: qianhui@chd.edu.cn; Tel.: +86-029-8233-9327
}

Received: 20 November 2017; Accepted: 18 December 2017; Published: 25 December 2017

\begin{abstract}
This study aims to reveal rainfall anomalies and changes over the Yellow River Basin due to the fragile ecosystem and rainfall-related disasters. Common trend analyses relate to overall trends in mean values. Therefore, we used two graphical methods: the quantile perturbation method (QPM) was used to investigate anomalies over time in extreme rainfall, and the partial trend method (PTM) was used to analyze rainfall changes at different intensities. A nonparametric bootstrap procedure is proposed in order to identify significant PTM indices. The QPM indicated prevailing positive anomalies in extreme daily rainfall 50 years ago and in the middle reaches during the 1970s and 1980s. The PTM detected significant decreases in annual rainfall mainly in the latter half of the middle reaches, two-thirds of which occurred in high and heavy rainfall. Most stations in the middle and lower reaches showed significant decreases in rainy days. Daily rainfall intensity had a significant increase at 13 stations, where rainy days were generally decreasing. The combined effect of these opposing changes explains the prevailing absence of change in annual rainfall, and the observed decreases in annual rainfall can be attributed to the decreasing number of rainy days. The changes in rainy days and rainfall intensity were dominated by the wet season and dry season, respectively.
\end{abstract}

Keywords: quantile perturbation method; partial trend method; innovative trend analysis; rainfall; extreme; anomaly; the Yellow River

\section{Introduction}

Climate change has been a hot topic for decades. Large numbers of studies have been carried out on global and regional scales [1]. Many studies have focused on changes in mean values [2,3]. Recently, the frequent occurrences of extreme weather and climatic events, such as rainstorms, heat waves, droughts and floods have been reported worldwide [1,4-7]. These extreme events are likely to bring about damaging effects on the ecosystem, society and economy [8-10]. Therefore, concerns about variations in extreme weather conditions are greatly increasing [11,12]. Disproportionate changes in rainfall intensity have been found all over the world. For example, changes in heavy rainfall have been larger than the mean rainfall when there were statistically significant regional changes in the rainy season [13]. Even changes in extreme rainfall were opposed to changes in mean rainfall in some regions [14]. Hence, it is necessary to investigate changes in different rainfall intensities.

The Yellow River Basin is known as the "cradle of Chinese civilization" and continues to play a critical role in the development of China [15]. The river is the primary water source for agriculture and industries, and supports a population of 107 million people who live in the river basin [16]. However, the flow shows a marked decline, especially in the lower reach where the main river has dried up 
(i.e., zero flow) since $1972[15,17,18]$. The frequency and duration of the drying up and zero-flow distance increased rapidly in the 1990s $[19,20]$. The Yellow River, also known as "China's Sorrow", is a river of disasters [21]. The river runs through the Loess Plateau, a highly erodible landform, and carries the soil downstream. It discharges over 1.0 billion tons of sediments annually [22,23]. The sediment is deposited as fine silt, which has elevated the river bed in the lower course where has reached greater heights than the surrounding plains [24]. As a result, the Yellow River has burst its banks 1593 times and has had 26 major changes of course in the past 2550 years [25]. High intensity rainfall in the Loess Plateau is a key inducement of this kind of disasters [21].

Although many scholars have studied variations in the streamflow of the Yellow River [26-29], variations in rainfall did not raise much concern. Rainfall is an important process in water cycle and is the primary water source of rivers. Several recent studies investigated rainfall variations in the Yellow River Basin. Xin et al. [30] investigated the rainfall trends at 60 stations of the Loess Plateau during the period 1965-2008, and found a statistically significant decreasing trend $(p<0.5)$ in annual rainfall at 7 stations which are mainly in the Wudinghe River Basin, the Fenhe River Basin and the north-central Shanxi Province. Hu et al. [12] revealed that most stations in the Yellow River source region had no significant changes in rainfall indices, including total rainfall, mean rainfall on wet days and maximum total rainfall from any consecutive 5 days, in the period of 1960-1990, 1960-2000 and 1960-2006. Yan et al. [31] found a decreasing trend in average annual rainfall based on 89 stations in the Yellow River Basin from 1961 to 2008 on 2, 4, 8 and 16 year timescales. Liang et al. [32] studied mean rainfall and extremes during 1961-2012 based on 62 stations. They observed 9 stations showing a significant decreasing trend $(p<0.5)$ in the eastern monsoon sub-region (mainly in the middle Yellow River), and 7 extreme rainfall indices showing prevailing negative values, however, only a few of them are significant. Tian and Yang [33] investigated trends in temperature and rainfall in the Yellow River, Yangtze and Pearl River Basins. They discovered no significant trend in annual and monthly rainfall over the period 1956-2013, but a significant decrease in annual rainfall in the Yellow River Basin during 1957-1997; they also discovered a marked decrease in extreme wet years and extreme wet months from the period 1956-1984 to the period 1985-2013.

The commonly used methods for these trend analyses are the Mann-Kendall test [34,35], Sen's slope [36] and linear regression [37]. These analyses are concerned with overall trends in mean values. However, they ignored changes over time. Significant changes in historical periods, which are anomalies of climatic variables, may be related to disastrous hydrometeorological events [38]. The quantile perturbation method (QPM) investigates the historic changes in the ranked extremes, and in the last decade, it has been widely used for meteorological and hydrological extremes [39-41]. Ntegeka and Willems [39] found that high rainfall extremes were clustered in the 1910s-1920s, the 1960s and the 1990s in the winter and summer at Uccle, which may have been an inducement of the increasing number of flood events in Belgium during the past 15 years. Tabari et al. [40] investigated anomalies in monthly river flow from 10 hydrometric stations in the Qazvin plain, Iran, and found a positive anomaly during the 1990s and a negative one during the 2000s. Willems [41] analyzed 10-min series of 108 years worth of precipitation in Brussels, and found multidecadal oscillation highs that occurred within a period of 35 to 45 years. Scholars generally consider trends in mean values when using the common trend analysis methods. While more studies investigated trends in extremes, disproportionate changes in variable categories did not raise much concern. Maybe it is because there is no clear definition of division between variable categories, and far more calculations need to be carried out for various variable categories. However, understanding disproportionate changes in different categories will reveal more characteristics and helpful information. The partial trend method (PTM) produces a graphical presentation to observe overall the trend, as well as trends in various categories at the same time. The PTM has been used to analyze trends in hydrological and meteorological variables, such as evaporations, temperature, rainfall, runoff and water quality [42-46]. Kisi [42] used the PTM to investigate trends in monthly pan evaporation at six stations in Turkey, and found that three stations without an overall trend has some increasing and decreasing trends for the low, medium and peak pan 
evaporation values. Wu and Qian [43] used the PTM to study the rainfall trend in Shaanxi Province, China; they found that light rainfall showed an increasing trend in summer, but a decreasing trend in other seasons. Dabanlı et al. [44] applied the Mann-Kendall test and the PTM to investigate relative humidity, temperature, precipitation and runoff from the Ergene drainage basin, Turkey. Although the Mann-Kendall test showed significant trends in almost none of the cases, the PTM indicated trends in some categories, such as an increasing trend in high and very high temperatures.

Most of the investigations of rainfall changes in the Yellow River basin have been mainly concerned with the mean of rainfall. This study attempts to apply two graphical methods to detect rainfall variations in the Yellow River Basin based on the latest high-quality data from the 1950s to 2016. The QPM analyzes anomalies of extreme rainfall with time, and the PTM detects the overall trend and trends in different intensities. The statistical significance of the QPM index is estimated by a nonparametric bootstrap method. However, there is no method to identify a statistically significant PTM index. Previous studies detected a marked change according to a $5 \%$ or $10 \%$ departure from a neutral line $[47,48]$. This judgment is, nevertheless, subjective and without statistical foundations. In this study, a nonparametric bootstrap procedure is proposed to identify the statistically significant PTM index. The broad applicability of the bootstrap procedure is a benefit, as it is a kind of modeling technique which is simple and does not rely on data distribution [49-54].

\section{Data and Methods}

\subsection{Study Area}

The Yellow River is the second longest river in China with a length of $5464 \mathrm{~km}$. The river originates in the Tibetan Plateau, wanders through northern semi-arid regions, crosses the loess plateau, passes through the North China Plain, and finally debouches into the Bohai Sea [55]. The Yellow River Basin covers arid, semi-arid and semi-humid regions, with average annual rainfall ranging from $123 \mathrm{~mm}$ to $1039 \mathrm{~mm}$. The Yellow River Basin is commonly divided into three reaches: the upper reach from the origin to Hekou, the middle reach from Hekou to Huayuankou (near Zhengzhou), and the lower reach from Huayuankou to the river mouth (Figure 1). The upper reach, accounting for over half of the basin, consumes nearly forty percent (13 billion cubes) of the surface water. The lower reach, accounting for only $3 \%$ of the basin, also consumes similar amounts of surface water [22,56,57]. Agriculture consumes 26 billion cubic meters of surface water per year, accounting for $78 \%$ of the surface water consumed.

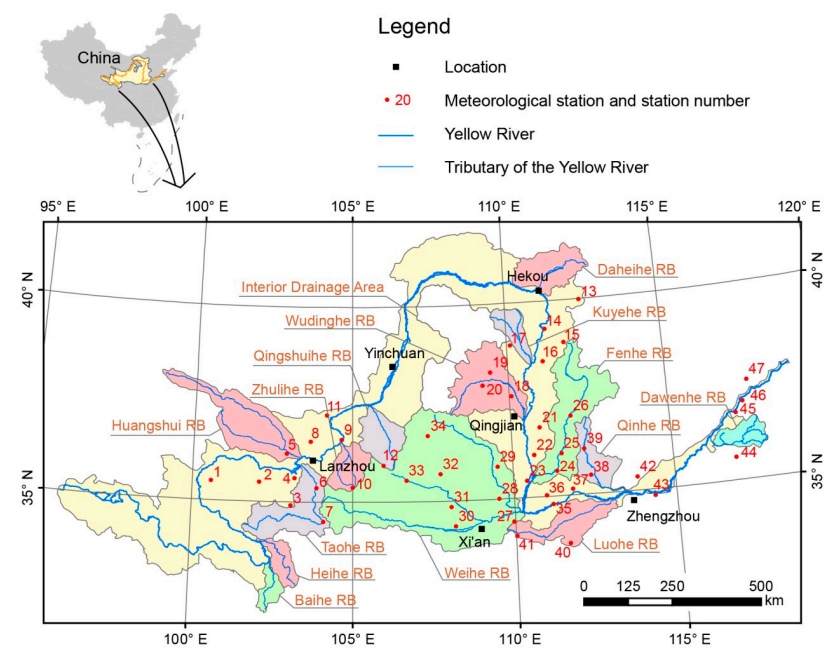

Figure 1. The inset map shows the location of the Yellow River Basin. The main map shows meteorological stations, some cities and important counties, the Yellow River and its tributaries, and sub-basins of the Yellow River Basin. The abbreviation RB stands for river basin. 


\subsection{Data}

The daily rainfall data were obtained from the China Meteorological Data Service Center. To detect anomalies and changes in a long-term period, the series should be as long as possible. A large number of stations were established in the 1950s, which gave the earliest records. Hence, the selected series start in the 1950s. To make full use of the most recent data, the end year for selected stations must be 2016. In a word, the period of selected series is from 1950s to 2016. To obtain high-quality a series, records ware checked according to two strict criteria: (1) series with missing data ware excluded, which means that selected stations do not have any missing data; (2) data were checked and corrected by extreme value theory and homogeneity tests, which means that selected series contain no error records, and questionable records must be less than $0.3 \%$ of the series. Accordingly, a total of 47 series were used in this study. The starting years, elevations and series lengths of the selected stations are shown in Table 1.

Table 1. Summary of meteorological stations used in this study, including start years of records, elevations of stations and proportions of questionable records.

\begin{tabular}{cccccccc}
\hline $\begin{array}{c}\text { Station } \\
\text { Number }\end{array}$ & Start Year & Elevation & $\begin{array}{c}\text { Questionable } \\
\text { Records (\%) }\end{array}$ & $\begin{array}{c}\text { Station } \\
\text { Number }\end{array}$ & Start Year & Elevation & $\begin{array}{c}\text { Questionable } \\
\text { Records (\%) }\end{array}$ \\
\hline 1 & 1957 & 3120.0 & 2.83 & 25 & 1954 & 449.5 & 0 \\
2 & 1958 & 2475.0 & 0 & 26 & 1954 & 746.0 & 0 \\
3 & 1958 & 2910.0 & 0 & 27 & 1953 & 2064.9 & 0 \\
4 & 1951 & 1917.2 & 0 & 28 & 1959 & 499.2 & 0.09 \\
5 & 1957 & 1813.9 & 0 & 29 & 1955 & 1155.9 & 0.04 \\
6 & 1951 & 1893.8 & 1.29 & 30 & 1955 & 471.0 & 2.61 \\
7 & 1951 & 2315.0 & 1.29 & 31 & 1959 & 994.6 & 2.88 \\
8 & 1958 & 1668.5 & 1.44 & 32 & 1951 & 1421.0 & 1.29 \\
9 & 1951 & 1398.2 & 1.20 & 33 & 1951 & 1346.6 & 1.29 \\
10 & 1958 & 2450.6 & 1.44 & 34 & 1957 & 1255.6 & 2.78 \\
11 & 1957 & 1630.9 & 1.32 & 35 & 1957 & 409.9 & 1.32 \\
12 & 1958 & 1916.5 & 1.39 & 36 & 1956 & 375.0 & 2.65 \\
13 & 1957 & 1345.8 & 0 & 37 & 1958 & 505.0 & 0 \\
14 & 1955 & 1036.0 & 2.69 & 38 & 1957 & 659.5 & 1.37 \\
15 & 1957 & 1401.0 & 0 & 39 & 1957 & 860.1 & 0 \\
16 & 1955 & 1012.6 & 0 & 40 & 1957 & 742.4 & 0 \\
17 & 1957 & 1098.0 & 1.41 & 41 & 1953 & 658.5 & 0 \\
18 & 1953 & 929.7 & 0.09 & 42 & 1951 & 73.2 & 2.49 \\
19 & 1951 & 1157.0 & 1.29 & 43 & 1951 & 73.7 & 2.49 \\
20 & 1954 & 1111.0 & 1.39 & 44 & 1951 & 51.7 & 1.29 \\
21 & 1957 & 1052.7 & 0 & 45 & 1951 & 170.3 & 0 \\
22 & 1957 & 851.3 & 0 & 46 & 1957 & 121.8 & 0 \\
23 & 1957 & 458.1 & 1.37 & 47 & 1951 & 11.7 & 1.20 \\
24 & 1957 & 433.8 & 0 & 0 & 0 & 0 & 0 \\
\hline
\end{tabular}

\subsection{Quantile Perturbation Method}

The QPM extracts a consecutive sub-series from the fully available series. The sub-series is a specified length of 5 to 15 years [58], set as 10 years in this study. The threshold for extremes was defined by the 99th percentiles, based on the full series. The extracted extremes needed to meet independent criteria. For aggregation times higher than $12 \mathrm{~h}$ (this study used daily rainfall, so the aggregation time was $24 \mathrm{~h}$ ), independent extremes separated by a time span equal to or greater than the aggregation time ware considered to be independent [41]. The same quantiles above the threshold from the sub-series and the full series were compared by

$$
\left(y_{1}-x_{1}\right) / x_{1},\left(y_{2}-x_{2}\right) / x_{2},\left(y_{3}-x_{3}\right) / x_{3}, \ldots,\left(y_{n}-x_{n}\right) / x_{n}
$$

where, $y_{1}, y_{2}, y_{3}, \ldots, y_{n}$ were extracted from a sub-series based on their values, which were larger than the threshold, and they were arranged in descending order; $x_{1}, x_{2}, x_{3}, \ldots, x_{n}$ are the corresponding quantiles from the full series. The linear interpolation was used to estimate quantiles that could not 
be directly found in the full series. The mean of these ratios is an anomaly percentage that measures the trend of the sub-period. The sub-period was assigned by moving window, which firstly put the sub-period at the beginning of the full series and subsequently shifted by 1 year at a time. Consequently, this procedure provided a large number of anomaly indices. Moreover, the moving window technique made the anomaly indices change smoothly with time [59]. The statistical significance of the anomalies was tested by confidence intervals, which were estimated by a nonparametric bootstrap method. For more information on the bootstrap procedure, refer to references $[39,60]$.

\subsubsection{Partial Trend Method}

The PTM was firstly introduced by Şen in 2012 [61], and it was also called innovative trend analysis in some studies [62]. It divides the full series into two or more equal parts. Due to limited data, this study divided the series into two halves. The two halves were sorted in ascending order. Then the first and second series were placed on the horizontal and the vertical axis, respectively, in a two-dimensional Cartesian coordinate system. If no change existed in the full series then, ideally, the two halves would be equal. If so, the points in the scatter plot would fall on the $45^{\circ}$ line. Otherwise, the points fall above and below the $45^{\circ}$ line, which indicates an increasing and a decreasing trend, respectively (Figure 2) [42,57].

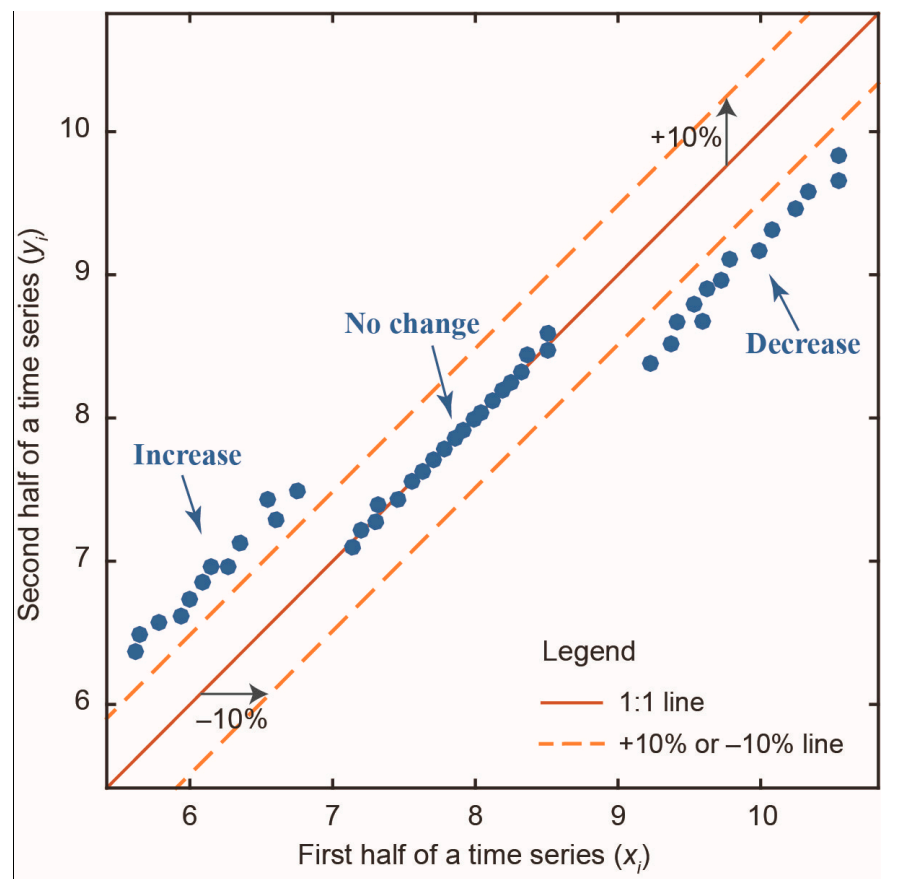

Figure 2. Illustration of the Partial Trend Method (PTM) plot for increasing, decreasing and no change regions.

A PTM index, derived by the theory above, was used to estimate the magnitude of a trend [43]. The overall trend of a series was calculated as follows.

$$
P I=\frac{1}{n} \sum_{i=1}^{n} P I_{i}=\frac{1}{n} \sum_{i=1}^{n} \frac{10\left(y_{i}-x_{i}\right)}{\bar{x}}
$$

where, PI is the PTM index; $x_{i}$ and $y_{i}$ are the $i$ th value of the ordered first and second sub-series, respectively; $\bar{x}$ is the average of $x_{i} ; 10$ is a coefficient to make the PTM index an appropriate magnitude to record. The partial trend, which indicates trends in different magnitudes, such as trends in extreme rainfall, is the mean of partial $P I_{i}$ instead of the entire magnitude from $P I_{1}$ to $P I_{n}$. Generally, rainfall is divided into 3 to 5 categories according to rainfall intensity $[44,47,63]$. To reveal disproportionate 
changes in rainfall intensity, this study divided annual rainfall equally into 5 categories based on quantiles: light rainfall, less than 20th percentile; low rainfall, 20th-40th percentile; moderate rainfall, 40th-60th percentile; high rainfall, 60th-80th percentile; heavy rainfall, larger than 80th percentile.

\subsubsection{Nonparametric Bootstrap Method}

The bootstrap method, developed in 1970s, is a class of Monte Carlo resampling technique based on a great number of simulated repetitions of the original experiment $[64,65]$. The accuracy of the bootstrap method does not rely on large numbers of original data, so it is appropriate and effective for limited data, such as that for rainfall, which is generally less than 100 years. For an unknown distribution, the nonparametric bootstrap method builds an empirical distribution, which is an efficient tool to obtain statistics [65]. Under the null hypothesis $H_{0}$ of no trend displayed by the time series, temporal change results from natural variability or randomness. The confidence intervals derived from bootstrap distributions are summarized as follows, which is same as the bootstrap for the QPM, in theory.

(1) Sample with replacement from the full series to obtain a bootstrap sample that has the same size as the full series.

(2) Apply the PTM to the bootstrap sample. This yields a series of individual trend indices $P I_{i}$. Then, the overall trend index $P I^{*}$ (summation $i=1$ to $n$ of $P I_{i}$ according to Formula 2) and partial trend indices $P I^{* *}$ (partial summation of $P I_{i}$ ) are calculated.

(3) Repeat steps 1 and $2 B$ times to obtain an estimate of the bootstrap distributions of $P I^{*}$ and $P I^{* *}$.

(4) Estimate the confidence intervals from the bootstrap distributions. For a given a significance level $\alpha$, the two-sided confidence intervals are estimated by the $100 \alpha / 2$ th and $100(1-\alpha / 2)$ th percentiles of the bootstrap distribution.

The bootstrap replicates $B$ should be a large number. Most scholars suggest that 1000 or 2000 replicates can satisfy a common application [66,67]. This study estimates the $5 \%$ and $1 \%$ significance levels with $B=5000$. For example, to estimate the $1 \%$ level, the $99 \%$ confidence intervals of $P I$ are defined by the 25 th and 4975 th values of the ordered $P I^{*}$.

\section{Results and Discussion}

\subsection{Temporal Anomaly in Extreme Daily Rainfall}

Temporal variations in extreme daily rainfall were investigated by the QPM. Due to limited space, only a sample of the QPM plots are shown in Figure 3. The results reflect that apart from a few stations (stations 11, 29, 36 and 43), stations had some perturbation factors falling outside the $95 \%$ confidence limits during the estimation period. This indicates that extreme rainfall has significant anomalies over time. An outstanding observation is that about half of the stations have showed significant positive anomalies 50 years ago. The significant anomalies can be observed in the Qinhe River Basin as well as in the Luohe River Basin (stations 38, 39 and 40). It is the extreme rainfall in these areas that caused severe floods in the lower reaches during the 1950s. Another cluster of positive anomalies was found to be prevailing in the middle reaches between Qingiian and Zhengzhou during the 1970s and 1980s. The positive anomalies in the Fenhe River Basin, Weihe River Basin and Luohe River Basin (stations $24,26,27,28,30,31,35,37,40$ and 41) during the 1980s also caused a severe flood. Significant negative anomalies were also detected. The lower extremes prevailed during the 1990s. During the last decade, the Yellow River Basin has generally showed a mean level of extremes that is based on the whole series, except for the middle reaches between Hekou and Qingjian (stations 14-20) where positive anomalies have been shown in recent years. 


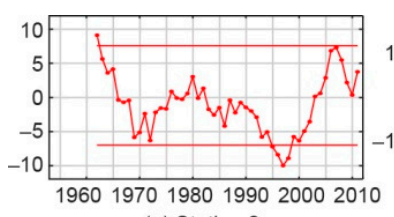

(a) Station 2

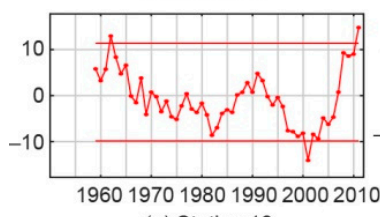

(e) Station 16
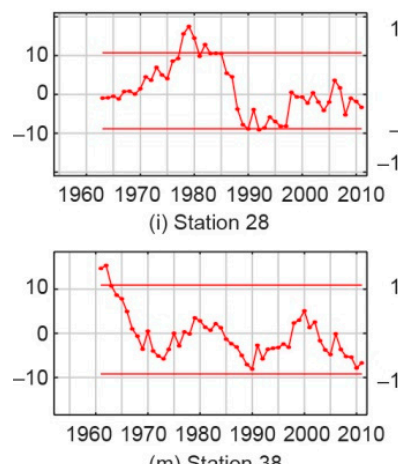

(m) Station 38

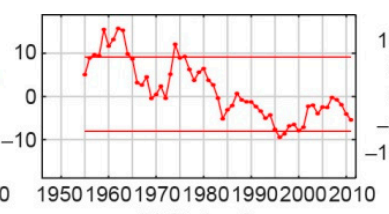

(b) Station 6

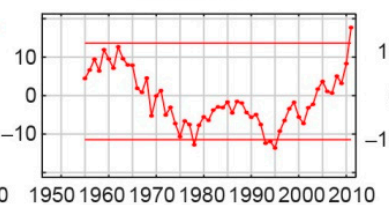

(f) Station 19
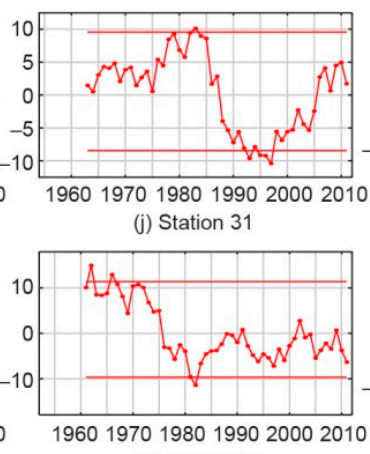

(n) Station 39

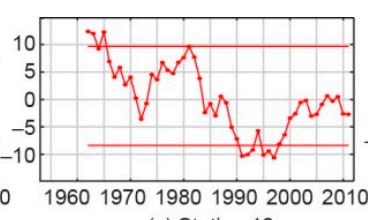

(c) Station 10

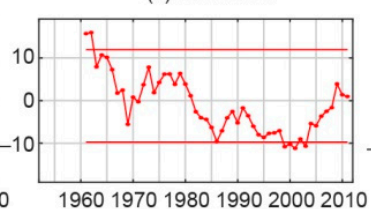

(g) Station 21

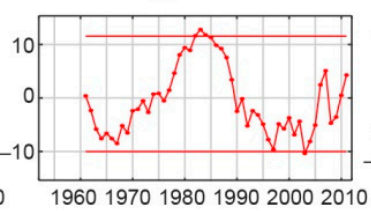

(k) Station 35

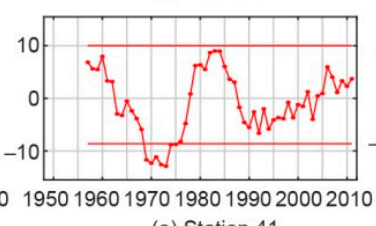

(o) Station 41
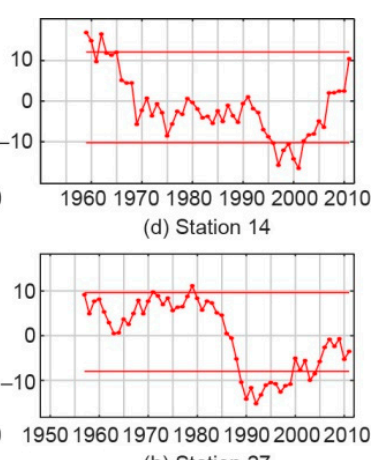

(h) Station 27
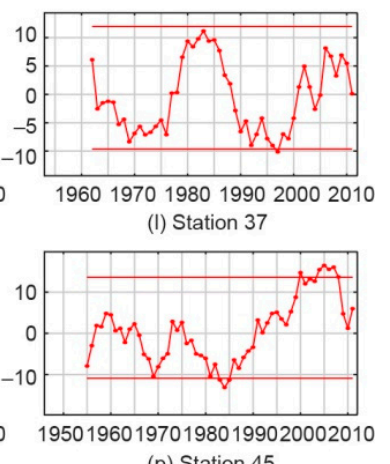

(p) Station 45

Figure 3. Temporal anomalies in extreme daily rainfall. The $y$-axis represents the anomaly index in percentage. The straight line denotes the $95 \%$ confidence intervals.

\subsection{Variations in Annual Rainfall}

Figure 4 shows changes in annual rainfall evaluated by the PTM (only a part of the PTM plots are shown due to limited space). The visual display provides primary insights into observing changes. Most of the points fall between the $\pm 10 \%$ lines indicating insignificant variations that are derived from natural variability or randomness. Some points fall outside of the $\pm 10 \%$ band, and they generally fall below the $-10 \%$ line. This indicates a prevailing decrease in some ranges of rainfall intensities at some stations. For instance, at station 6 , points with a large value fall below the $-10 \%$ line suggesting a decrease in abundant annual rainfall. More specifically, the maximum annual rainfall in the second period (the last 33 years) was $641 \mathrm{~mm}$ and, by contrast, 8 years in the first period (accounting for $24.2 \%$ ) had annual rainfall that is larger than $641 \mathrm{~mm}$. Different from the prevailing behavior, stations 1,45 and 46 exhibited a possibility of increase in some intensities. However, it is difficult to identify a significant change due to points collected on the $-10 \%$ line.

The PTM index is applied to analyze changes in annual rainfall, and corresponding significant levels are identified by the nonparametric bootstrap method. Figure 4 shows $95 \%$ confidence intervals for the overall trend, which is close to the $\pm 10 \%$ lines. The PTM index (Table 2) indicates that 7 stations (accounting for 14.9\%) showed a significant decrease in annual rainfall. Except at station 10, the significant decrease was located in the latter half of the middle reaches (the Fenhe River Basin, the lower reaches of the Weihe River and the area between them; Figure 5a). Changes in different intensities of annual rainfall that range from light to heavy rainfall (defined above) were investigated by the PTM index. The results (Table 2) indicate that significant changes accounted for $12.8 \%$ of all the estimates. The PTM index validated the changes observed from the PTM plots, such as the data from station 6 (analyzed previously), where a decrease in heavy rainfall has been identified by the PTM index with the significance level of 5\%. The PTM index examined the possibility of the increases observed by the PTM plot at the stations 1, 45 and 46. The results indicate that an increase was observed only at the station 46, and was confined to low, moderate and high rainfall. Apart from station 46 , significant changes were decreases, about two-thirds of which occurred in the range of 
high and heavy rainfall. From the spatial view, the decreases were concentrated mainly in the middle reaches. It is noticeable that station 27 exhibited a decrease at the $1 \%$ significance level for annual rainfall and rainfall in various intensities. As seen from the PTM plot, all points for station 27 fall below the $-10 \%$ line with similar distances to the neutral line. Station 27 , a high-altitude station with an elevation of $2064.9 \mathrm{~m}$ on the top of Mount Hua, has a special environment that is different from other stations. This implies that elevation has an important impact on rainfall changes.
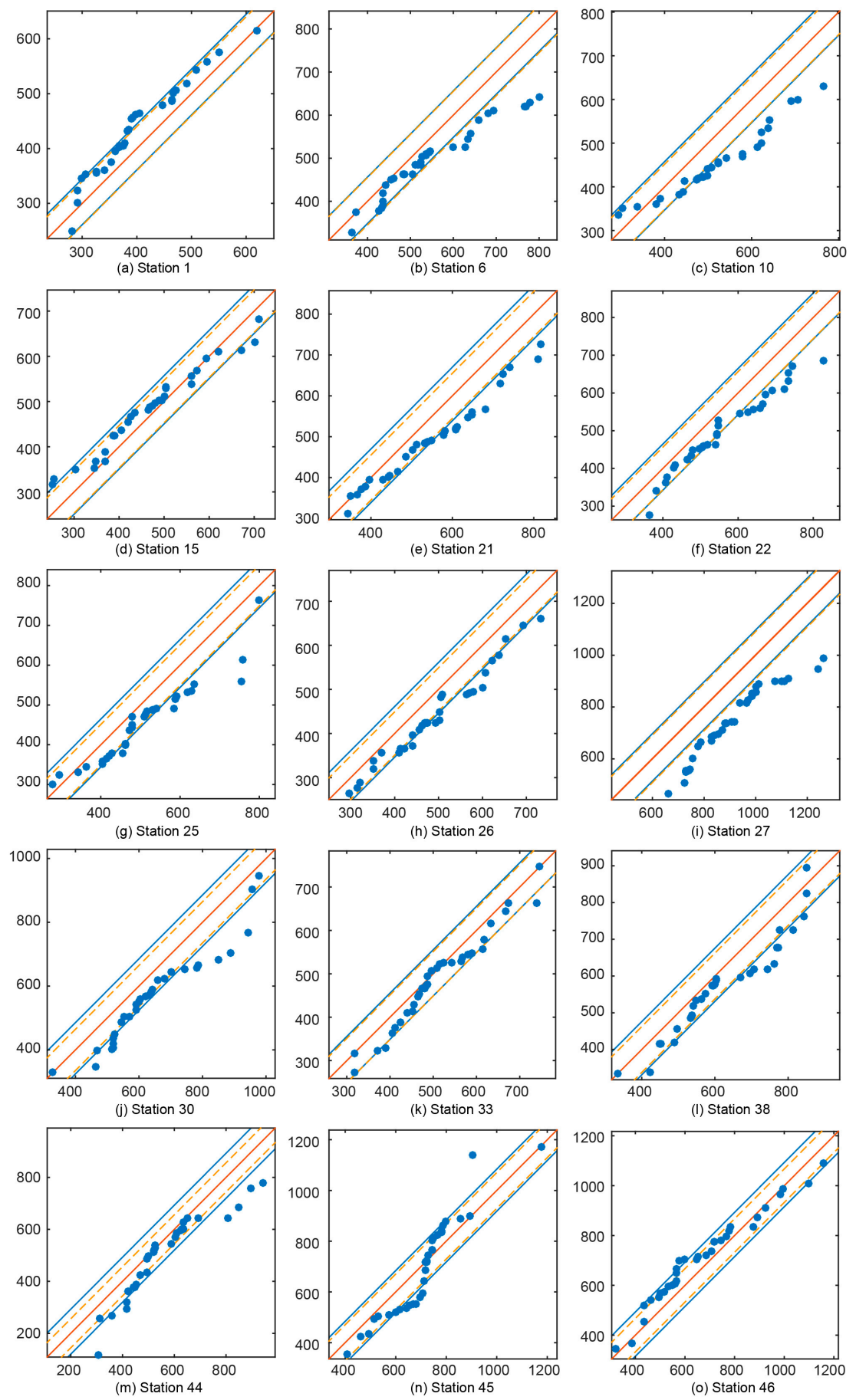

Figure 4. PTM plots for annual rainfall. The solid diagonal red line is the 1:1 line, the upper and lower dashed lines are the $+10 \%$ and $-10 \%$ lines respectively, and the solid blue line is the boundary of $95 \%$ confidence intervals for the overall trend estimated by the nonparametric bootstrap procedure. (Unit: $\mathrm{mm}$ ). 
Table 2. Changes in annual rainfall according to the PTM index for annual rainfall and rainfall in different intensities, including light, low, moderate, high and heavy rainfall.

\begin{tabular}{|c|c|c|c|c|c|c|}
\hline $\begin{array}{l}\text { Station } \\
\text { Number }\end{array}$ & $\begin{array}{l}\text { Annual } \\
\text { Rainfall }\end{array}$ & $\begin{array}{c}\text { Light } \\
\text { Rainfall }\end{array}$ & $\begin{array}{c}\text { Low } \\
\text { Rainfall }\end{array}$ & $\begin{array}{c}\text { Moderate } \\
\text { Rainfall }\end{array}$ & $\begin{array}{c}\text { High } \\
\text { Rainfall }\end{array}$ & $\begin{array}{c}\text { Heavy } \\
\text { Rainfall }\end{array}$ \\
\hline 1 & 0.81 & 0.56 & 0.74 & 1.20 & 0.97 & 0.60 \\
\hline 2 & -0.23 & -0.14 & 0.04 & 0.60 & -0.13 & -1.48 \\
\hline 3 & -0.15 & 0.16 & 0.37 & -0.12 & -0.11 & -0.98 \\
\hline 4 & 0 & 0.41 & 0.56 & 0.06 & -0.58 & -0.37 \\
\hline 5 & -0.20 & 0.54 & 0.47 & 0.56 & -0.47 & $-2.09 *$ \\
\hline 6 & -0.99 & -0.64 & -0.33 & -0.56 & -1.13 & $-2.17 *$ \\
\hline 7 & -0.48 & -0.70 & -0.47 & -0.60 & -0.25 & -0.43 \\
\hline 8 & -0.04 & 0.48 & 0.71 & 0.52 & -0.17 & -1.64 \\
\hline 9 & -0.17 & 0.07 & 0.18 & -0.13 & -0.12 & -0.82 \\
\hline 10 & $-1.24 *$ & 0.27 & -1.00 & -1.27 & $-1.94 *$ & $-2.02 *$ \\
\hline 11 & 0.30 & -0.38 & 0.67 & 0.46 & 0.31 & 0.45 \\
\hline 12 & -0.63 & 0.11 & -0.23 & -0.76 & -1.18 & -0.99 \\
\hline 13 & -0.24 & 0.82 & 0.07 & 0.50 & -0.19 & -2.39 * \\
\hline 14 & -0.74 & 0.05 & -0.36 & -0.46 & -0.75 & $-1.97 *$ \\
\hline 15 & 0.28 & 0.75 & 0.69 & 0.42 & 0.16 & -0.61 \\
\hline 16 & 0.06 & 1.02 & 0.78 & 0.26 & -0.51 & -1.09 \\
\hline 17 & 0 & 0.69 & 0.05 & 0.30 & -0.33 & -0.69 \\
\hline 18 & -1.02 & -0.89 & $-1.15 *$ & -0.95 & -0.99 & -1.10 \\
\hline 19 & 0.06 & 0.56 & 0.26 & 0.20 & -0.14 & -0.49 \\
\hline 20 & -0.83 & 0.49 & -0.31 & -0.91 & $-1.43 *$ & -1.81 * \\
\hline 21 & $-1.04 *$ & -0.15 & -0.72 & -1.00 & $-1.64 *$ & -1.69 * \\
\hline 22 & $-1.11 *$ & -0.74 & -0.74 & -0.87 & $-1.45 *$ & -1.76 * \\
\hline 23 & -0.38 & -0.10 & -0.13 & -0.13 & -0.27 & -1.28 \\
\hline 24 & -0.68 & -0.48 & -0.13 & -0.61 & -0.54 & -1.64 \\
\hline 25 & $-1.07 *$ & -0.27 & $-1.13 *$ & -0.59 & -1.18 & $-2.00 *$ \\
\hline 26 & $-1.04 *$ & -0.56 & $-1.09 *$ & -1.12 & -1.12 & -1.27 \\
\hline 27 & $-1.84^{* *}$ & $-2.07 * *$ & $-1.55 * *$ & $-1.69 * *$ & $-1.52 * *$ & $-2.33^{* *}$ \\
\hline 28 & -0.91 & -0.10 & -0.56 & -0.79 & $-1.69 *$ & -1.26 \\
\hline 29 & -0.64 & -0.51 & -0.05 & -0.91 & -0.77 & -0.92 \\
\hline 30 & $-1.21 *$ & $-1.31 *$ & $-1.03 *$ & -0.80 & -0.92 & $-1.90 *$ \\
\hline 31 & -0.74 & -0.58 & -0.90 & -0.67 & -0.50 & -1.01 \\
\hline 32 & -0.57 & -0.86 & -0.26 & -0.33 & -1.00 & -0.40 \\
\hline 33 & -0.47 & -0.77 & -0.48 & -0.03 & -0.42 & -0.62 \\
\hline 34 & -0.26 & -0.38 & -0.31 & -0.94 & 0.51 & -0.14 \\
\hline 35 & -0.62 & -0.73 & -0.76 & 0.09 & -0.69 & -1.01 \\
\hline 36 & -0.79 & -0.64 & -0.95 & -0.76 & -0.83 & -0.76 \\
\hline 37 & -0.10 & -0.65 & -0.07 & 0.23 & -0.18 & 0.10 \\
\hline 38 & -0.78 & -0.71 & -0.52 & -0.29 & $-1.60 *$ & -0.79 \\
\hline 39 & -0.55 & -0.24 & 0.01 & -0.10 & -1.04 & -1.39 \\
\hline 40 & -0.69 & -0.52 & -0.39 & -0.60 & -0.43 & -1.48 \\
\hline 41 & -0.48 & -0.33 & -0.31 & -0.21 & -0.07 & -1.36 \\
\hline 42 & -0.51 & -0.52 & -0.01 & -1.07 & -0.79 & -0.24 \\
\hline 43 & -0.09 & -0.26 & -0.38 & -0.18 & -0.10 & 0.42 \\
\hline 44 & -0.19 & -0.60 & $-1.48 *$ & -0.52 & 0.59 & 0.96 \\
\hline 45 & 0.55 & 0.62 & 0.92 & 1.21 & 0.64 & -0.55 \\
\hline 46 & 0.94 & -0.18 & $1.15 *$ & $1.79 *$ & $1.63 *$ & 0.33 \\
\hline 47 & -0.30 & -0.45 & -0.31 & 0.22 & 0.16 & -1.09 \\
\hline
\end{tabular}

Note: * Statistically significant trends at the $5 \%$ significance level; ${ }^{* *}$ Statistically significant trends at the $1 \%$ significance level. 

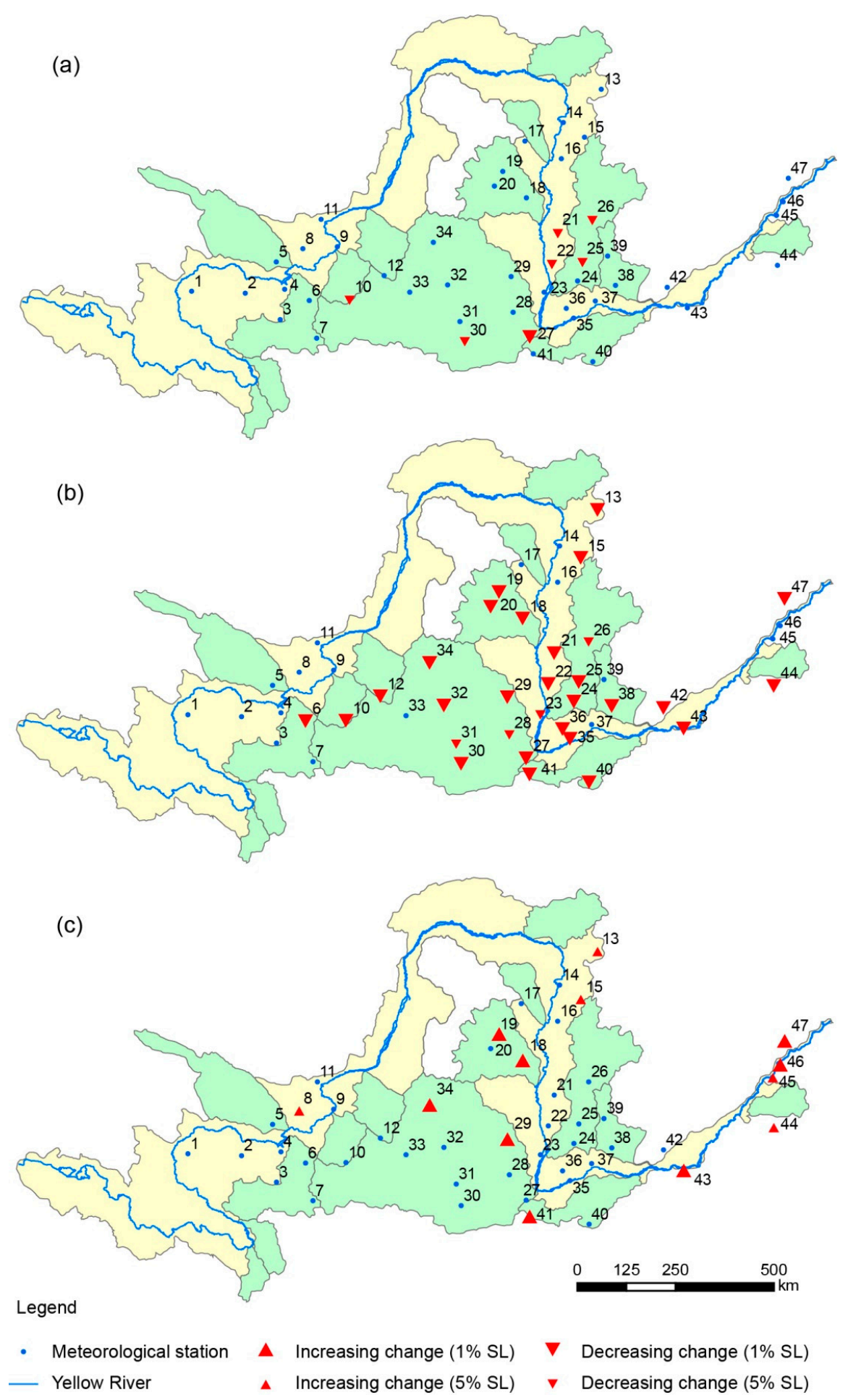

Figure 5. Significant changes in (a) annual rainfall; (b) rainy days and (c) average daily rainfall intensity in the Yellow River Basin detected by the PTM index. The abbreviation SL stands for significance level.

\subsection{Variations in Rainy Days and Daily Rainfall Intensity}

The PTM index (Table 3) shows that 30 stations, accounting for $64 \%$, have experienced a significant decrease in the annual number of rainy days. The decrease was dominated by the middle and lower reaches, as most of the decreases occurred in these areas and achieved the significance level of $1 \%$. Moreover, the majority of stations in the middle and lower reaches (accounting for $77 \%$ ) displayed 
a significant decrease in rainy days (Figure $5 b$ ). There are 13 stations, accounting for $28 \%$, that experienced significant increases in average intensity of daily rainfall (Table 3). These stations with increasing rainfall intensity generally had a decrease in rainy days (Figure $5 b, c$ ). This compensation of opposite changes explains the absence of change in the total annual rainfall. Still, some stations exhibited a decrease in rainy days without a change in rainfall intensity. As a consequence, annual rainfall exhibited a decrease for these stations. It is concluded that the observed decline in annual rainfall results from the decrease of rainy days.

Table 3. Changes in rainy day and average daily rainfall intensity by the PTM index for the dry and wet seasons.

\begin{tabular}{|c|c|c|c|c|c|c|}
\hline \multirow{2}{*}{$\begin{array}{l}\text { Station } \\
\text { Number }\end{array}$} & \multicolumn{3}{|c|}{ Rainy Day } & \multicolumn{3}{|c|}{ Rainfall Intensity } \\
\hline & All Season & Dry Season & Wet Season & All Season & Dry Season & Wet Season \\
\hline 1 & 0.19 & 0.31 & -0.17 & 0.58 & 0.51 & 0.68 \\
\hline 2 & -0.22 & -0.06 & -0.61 & -0.02 & -0.14 & 0.01 \\
\hline 3 & -0.39 & -0.01 & $-1.10 * *$ & 0.35 & 0.61 & 0.11 \\
\hline 4 & -0.11 & 0.34 & $-0.98^{* *}$ & 0.13 & 0.64 & 0.10 \\
\hline 5 & 0.02 & 0.08 & -0.41 & -0.12 & 0.38 & -0.52 \\
\hline 6 & $-1.22 * *$ & $-1.31 * *$ & $-1.54 * *$ & 0.23 & $1.34 *$ & -0.12 \\
\hline 7 & -0.58 & -0.45 & $-0.91 * *$ & 0.08 & 0.33 & 0.01 \\
\hline 8 & -0.93 & -0.12 & $-1.94 * *$ & $1.13 *$ & 1.48 & 0.78 \\
\hline 9 & -0.60 & -0.15 & -0.98 & 0.49 & 1.31 & -0.21 \\
\hline 10 & $-1.12 * *$ & $-0.82 *$ & $-1.86 * *$ & -0.11 & 0.53 & -0.26 \\
\hline 11 & 0.05 & 0.97 & -0.75 & 0.25 & 0.19 & 0.31 \\
\hline 12 & $-1.34 * *$ & $-1.01 *$ & $-2.02 * *$ & 0.85 & 1.21 & 0.99 \\
\hline 13 & $-1.11 * *$ & -0.45 & $-1.90 * *$ & $1.05 *$ & $1.72 *$ & 1.20 \\
\hline 14 & -0.75 & -0.58 & $-1.07 *$ & 0.18 & 0.95 & -0.58 \\
\hline 15 & $-0.85 * *$ & -0.59 & $-1.40 * *$ & $1.38 *$ & $1.92 * *$ & 1.42 \\
\hline 16 & -0.66 & -0.28 & $-1.16^{* *}$ & 0.97 & 1.15 & 0.62 \\
\hline 17 & -0.48 & -0.01 & $-1.16^{*}$ & 0.65 & 0.80 & 0.50 \\
\hline 18 & $-2.13 * *$ & $-1.89 * *$ & $-2.49 * *$ & $1.35 * *$ & 0.87 & $1.59 *$ \\
\hline 19 & $-1.26^{* *}$ & -0.86 & $-1.76^{* *}$ & $1.60 * *$ & 1.35 & 1.43 \\
\hline 20 & $-1.31 * *$ & -0.80 & $-2.06 * *$ & 0.60 & $2.08 *$ & -0.26 \\
\hline 21 & $-0.97^{* *}$ & -0.71 & $-1.44^{* *}$ & -0.01 & -0.27 & 0.21 \\
\hline 22 & $-1.15^{* *}$ & $-0.98 *$ & $-1.60 * *$ & 0.04 & 0.78 & -0.22 \\
\hline 23 & $-0.95 *$ & -0.71 & $-1.44^{* *}$ & 0.71 & 0.68 & 1.01 \\
\hline 24 & $-1.49^{* *}$ & $-1.29 *$ & $-1.95 * *$ & 1.02 & 1.22 & 1.00 \\
\hline 25 & $-1.32 * *$ & $-1.14 *$ & $-1.82 * *$ & 0.36 & 0.86 & 0.44 \\
\hline 26 & $-0.99 *$ & -0.76 & $-1.47^{* *}$ & -0.10 & -0.17 & 0.18 \\
\hline 27 & $-1.32 * *$ & $-1.30 * *$ & $-1.44^{* *}$ & -0.58 & -0.75 & -0.31 \\
\hline 28 & $-0.96 *$ & $-1.10 *$ & -0.87 & 0.13 & 0.78 & -0.48 \\
\hline 29 & $-1.62 * *$ & $-1.24 * *$ & $-1.97 * *$ & $1.21 * *$ & $1.32 * *$ & 1.19 \\
\hline 30 & $-1.43^{* *}$ & $-1.19 * *$ & $-1.62 * *$ & 0.28 & 0.63 & 0.17 \\
\hline 31 & $-0.87^{*}$ & $-0.96 *$ & -0.88 & 0.09 & 0.12 & 0.13 \\
\hline 32 & $-0.97^{* *}$ & -0.68 & $-1.56 * *$ & 0.43 & 0.32 & 0.91 \\
\hline 33 & -0.43 & -0.22 & $-0.91 *$ & 0 & 0.11 & 0.07 \\
\hline 34 & $-1.62 * *$ & $-1.44 *$ & $-1.95 * *$ & $1.60^{* *}$ & $1.79^{* *}$ & 1.49 \\
\hline 35 & $-0.96 * *$ & -0.73 & $-1.62 * *$ & 0.32 & 0.43 & 0.70 \\
\hline 36 & $-1.11 * *$ & $-0.89 *$ & $-1.48^{*}$ & 0.17 & 0.72 & -0.65 \\
\hline 37 & -0.06 & 0.03 & -0.65 & -0.06 & 0.23 & -0.41 \\
\hline 38 & $-0.94 * *$ & -0.66 & $-1.62 * *$ & 0.23 & 0.36 & 0.32 \\
\hline 39 & -0.60 & -0.31 & $-1.34^{* *}$ & 0.08 & 0.35 & 0.35 \\
\hline 40 & $-1.13 * *$ & $-0.85^{*}$ & $-1.71 * *$ & 0.54 & 0.36 & 0.72 \\
\hline 41 & $-1.71 * *$ & $-1.61 * *$ & $-1.82 * *$ & $1.47 * *$ & $1.93 * *$ & 1.31 \\
\hline 42 & $-1.08^{* *}$ & $-1.24 *$ & -0.97 & 0.60 & 0.92 & 0.33 \\
\hline 43 & $-1.71^{* *}$ & $-1.85 * *$ & $-1.58 * *$ & $1.72 * *$ & 1.04 & 2.10 * \\
\hline 44 & $-1.22 * *$ & $-1.57^{* *}$ & $-0.95 *$ & $1.11 *$ & $2.09 *$ & 0.25 \\
\hline 45 & -0.56 & -0.71 & -0.41 & $1.34 *$ & 1.54 & 1.36 \\
\hline 46 & -0.85 & -0.58 & $-1.42 *$ & $1.91 * *$ & $2.37 * *$ & 2.19 * \\
\hline 47 & $-2.14^{* *}$ & $-2.23 * *$ & $-2.19 * *$ & $2.09 * *$ & $2.40 *$ & $2.40 *$ \\
\hline
\end{tabular}

Note: ${ }^{*}$ Statistically significant trends at the $5 \%$ significance level; ${ }^{* *}$ Statistically significant trends at the $1 \%$ significance level. 
Rainfall distributes unevenly in time. More than half of the rainfall occurred in July, August and September. These 3 months are defined as the wet season, and the other 9 months are defined as the dry season. Variations in rainy days and rainfall intensity were investigated in the dry and wet seasons, respectively. The results (Table 3) show different performances between the two seasons. With respect to rainy days, 20 stations and 37 stations had significant decreases in the dry and wet seasons, respectively. In the wet season, 31 stations had a decrease in the number of rainy days that achieves the $1 \%$ significance level, which is far more than the amount ( 9 stations) in the dry season. It is rather remarkable that 10 stations saw no change in annual rainy days, but experienced a significant decrease in the wet season. In conclusion, therefore, it can be seen that rainy days are more prone to decreasing in the wet season, which contributed greatly to the decrease in annual rainy days. From the spatial view, the decrease in the annual number of rainy days is dominated by the middle reaches, as $90 \%$ of the stations in this area exhibited decreasing rainy days. The significant increase in rainfall intensity occurred at 10 stations in the dry season, and occurred at 4 stations in the wet season. This indicates that the increase in average rainfall intensity is mainly caused by the change in the dry season.

These changes in rainfall may create a negative impact on the environment. In the wet season, stations in the upper and middle reaches generally have dropped tremendously in the number of rainy days, but without changes in rainfall intensity. This implies a marked decrease in rainfall amount throughout the wet season, which may increase the occurrence of droughts as well as aggravate them, as droughts are more likely to occur in the wet season [68]. Without changes in rainfall intensity in the upper and middle reaches, changes in the wet season would have little impact on flooding. In the lower reaches, rainfall intensity displayed significant increases at some stations. In spite of this, the small watershed areas minimize its impact on flooding. The areas with a decreased number of rainy days and amount of annual rainfall (the Fenhe River Basin, the lower reaches of the Weihe River and the area between them) are suffering from more dry days and less water, which will worsen the fragile ecosystem. The areas with decreasing rainy days and increasing rainfall intensities may aggravate the uneven rainfall in time, thus reducing water-use efficiency. As the average rainfall intensity increases in some areas, the change in extreme daily rainfall is analyzed in the next section.

\subsection{Variations in Extremes of Daily Rainfall}

Variations in annual maximum daily rainfall, i.e., annual maximum consecutive 1-day rainfall (RX1day), were investigated with the PTM method. The results (Figure 6a) indicate 3 stations (stations 6,35 and 36) with a significant decrease. Rainfall duration was as long as a few days in some cases. Thus, variations in annual maximum consecutive 5-day rainfall (RX5day) were investigated in order to analyze the change in a continuous extreme rainfall. The results (Figure $6 \mathrm{~b}$ ) indicate that stations 6 and 10 showed a significant decrease in RX5day.

Sometimes the RX1day and RX5day were outliers, which may not reflect a universal change of extreme rainfall. Thus, more extremes should be extracted from daily rainfall. The 99th percentile was used as the threshold to obtain more extremes (R99) for the first and second series, respectively. Consequently, a year has 3.65 extremes on average. The independence criterion was also applied in the procedure of extraction. More significant changes were found in this index. Seven stations showed significant changes in R99 (Figure 6c), and the 4 stations detected to be decreasing in RX1day or RX5day also show significant decreases in R99. Additionally, R99 was detected to be increasing at stations 34 and 48. Rainfall is one of the main triggers of frequent landslides in these areas. The observed decrease in daily rainfall extremes is expected to decrease occurrences of landslides $[69,70]$. 

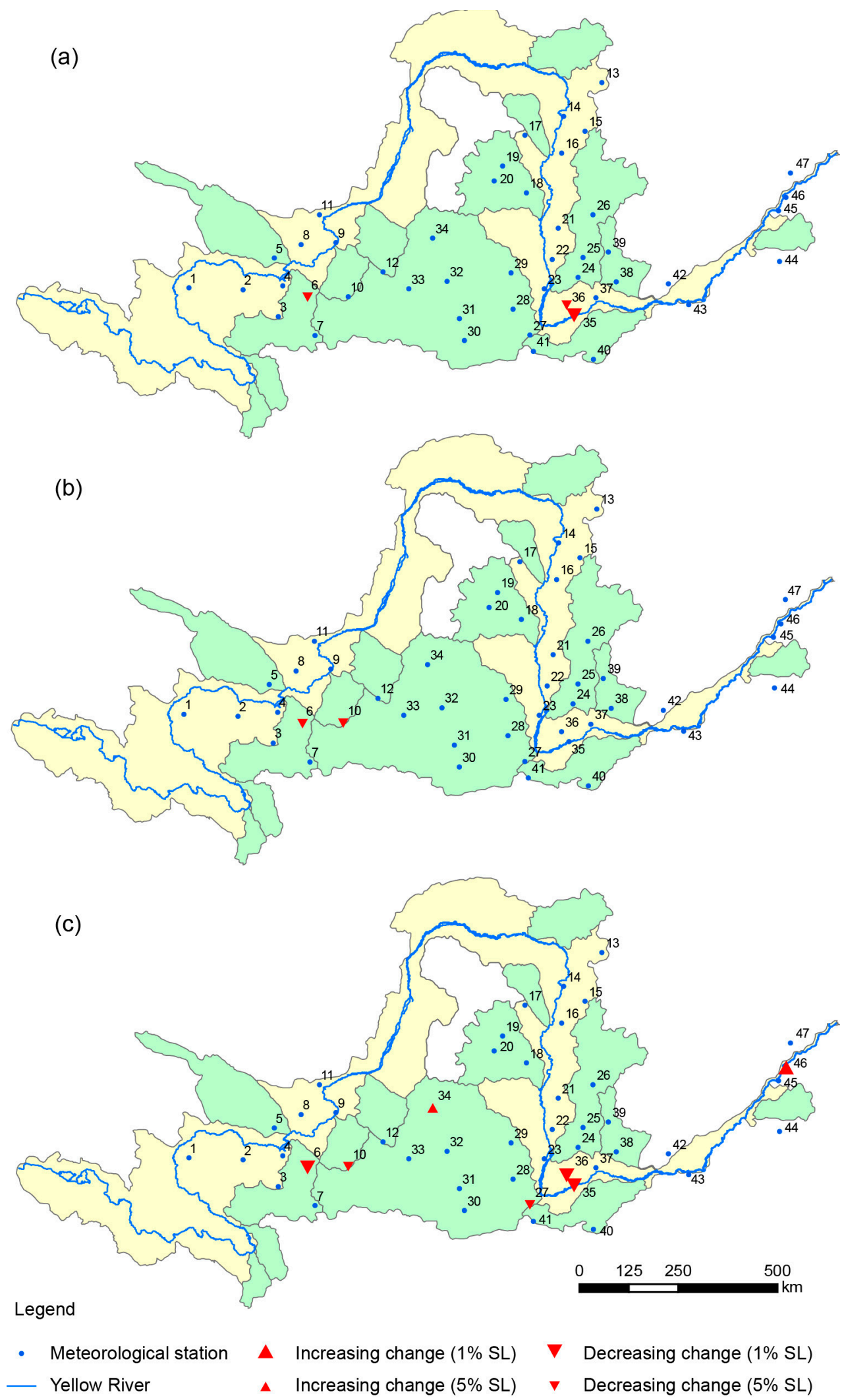

Figure 6. Significant changes in (a) annual maximum consecutive 1-day rainfall (RX1day); (b) annual maximum consecutive 5-day rainfall (RX5day) and (c) extreme daily rainfall that is larger than the 99th percentile (R99) in the Yellow River Basin detected by the PTM index. The abbreviation SL stands for significance level. 


\section{Conclusions}

In this paper, two graphical methods were used to analyze anomalies and changes in rainfall in the Yellow River Basin, based on high-quality rainfall data. The major conclusions are given as follows:

(1) Previous studies generally have estimated an overall trend in a specified period, but have taken no notice of changes over time. The QPM has been used to analyze anomalies in extremes of daily rainfall since 1950s. The results show that about half of the stations had significant positive anomalies in extreme daily rainfall 50 years ago. Another cluster of positive anomalies was found to be prevailing in the middle reaches during the 1970s and 1980s. Severe floods occurred during the corresponding periods of the two clusters of positive anomalies. In recent years, the middle reaches between Hekou and Qingjian have also showed positive anomalies.

(2) Changes in annual rainfall were observed with the PTM plot, and significant changes were further verified by the combination of the PTM index and the nonparametric bootstrap procedure. Annual rainfall was found to be significantly decreasing at 7 stations, mainly located in the latter half of the middle reaches. This is consistent with previous studies. However, previous studies neglected changes in different rainfall intensities, which are easily observed with the PTM plot. This study assessed changes in annual rainfall in five categories including light, low, moderate, high and heavy rainfall. Significant changes were found in $12.8 \%$ of all the estimates. Significant decreases were mostly in the middle reaches. About two-thirds of the significant decreases occurred in high and heavy rainfall.

(3) Changes in rainfall structures in the Yellow River Basin have not been investigated. This study has used the PTM to analyze changes in the annual number of rainy days and daily rainfall intensity, and their changes in the wet and dry seasons. The results indicate that $64 \%$ of the stations experienced significant decreases in rainy days, and $28 \%$ of the stations experienced significant increases in daily rainfall intensity. Most stations in the middle and lower reaches showed a significant decrease in rainy days. The stations with increasing rainfall intensity generally also had a decrease in rainy days. The compensation resulted in no change to the total annual rainfall. Still, some stations had a decreasing number of rainy days without a change in rainfall intensity. Thus, the observed decreases in annual rainfall can be attributed to the decreases in rainy days. There were nearly twice as many stations with a decreasing number of rainy days during the wet season compared with during the dry season, which indicates that rainy days had a more marked decrease in the wet season. Another important finding is that 10 stations showed no change in annual rainy days but a decrease in the wet season. In contrast, the increases in rainfall intensity mainly occurred in the dry season.

(4) Variations in extremes of daily rainfall were investigated with the PTM method. RX1day and RX5day showed a significant decrease only in 3 and 2 stations, respectively. R99 showed a significant decrease in 7 stations, including the stations with decreasing RX1day or RX5day.

These results are expected to provide insights for water resources planning, and the two graphical methods are expected to be useful for analyzing changes and anomalies in various fields, not limited to rainfall. Using high-quality data for analysis in this study provided reliable results. However, it involved limited stations, which cannot analyze the relationships between rainfall changes and geographical factors, such as landform and elevation. Although this study makes full use of the records, the series are still too short to discover a circulation of anomalies in extreme daily rainfall. Therefore, high-density stations with long-term observation will provide better understanding of rainfall changes. Further research is required in order to analyze changes in other hydrometeorological variables, and study the relationships between them.

Acknowledgments: The research was supported by the Special Fund for Scientific Research on Public Interest of the Ministry of Water Resources (201301084), the National Natural Science Foundation of China (41572236 and 41172212) and the Foundation for the Excellent Doctoral Dissertation of Chang'an University (310829165005). The rainfall data was obtained from China Meteorological Data Service Center (http://data.cma.cn/en). 
The authors would like to thank the reviewers for their insightful comments that greatly improved the quality of the paper.

Author Contributions: H. Qian provided the writing ideas and supervised the study; H. Wu conceived and designed the methods; X. Li was responsible for data collection and diagraming; all the authors wrote the paper, and were responsible for data processing and data analysis.

Conflicts of Interest: The authors declare no conflict of interest.

\section{References}

1. Intergovernmental Panel on Climate Change (IPCC). Climate Change 2013: The Physical Science Basis; Working Group I Contribution to the Fifth Assessment Report of the Intergovernmental Panel on Climate Change; Cambridge University Press: Cambridge, UK, 2013.

2. $\quad$ Peterson, T.C. Climate change indices. World Meteorol. Organ. Bull. 2005, 54, 83-86.

3. Wang, W.; Shao, Q.; Yang, T.; Peng, S.; Yu, Z.; Taylor, J.; Xing, W.; Zhao, C.; Sun, F. Changes in daily temperature and precipitation extremes in the Yellow River Basin, China. Stoch. Environ. Res. Risk Assess. 2013, 27, 401-421. [CrossRef]

4. Wilhelmi, O.V.; Wilhite, D.A. Assessing vulnerability to agricultural drought: A Nebraska case study. Nat. Hazards 2002, 25, 37-58. [CrossRef]

5. Mueller, E.N.; Pfister, A. Increasing occurrence of high-intensity rainstorm events relevant for the generation of soil erosion in a temperate lowland region in Central Europe. J. Hydrol. 2011, 411, 266-278. [CrossRef]

6. Kundzewicz, Z.W.; Kanae, S.; Seneviratne, S.I.; Handmer, J.; Nicholls, N.; Peduzzi, P.; Mechler, R.; Bouwer, L.M.; Arnell, N.; Mach, K.; et al. Flood risk and climate change: Global and regional perspectives. Hydrol. Sci. J. 2013, 59, 1-28. [CrossRef]

7. Habeeb, D.; Vargo, J.; Stone, B. Rising heat wave trends in large US cities. Nat. Hazards 2015, 76, 1651-1665. [CrossRef]

8. Hallegatte, S.; Green, C.; Nicholls, R.J.; Corfee-Morlot, J. Future flood losses in major coastal cities. Nat. Clim. Chang. 2013, 3, 802-806. [CrossRef]

9. Deryng, D.; Conway, D.; Ramankutty, N.; Price, J.; Warren, R. Global crop yield response to extreme heat stress under multiple climate change futures. Environ. Res. Lett. 2014, 9, 034011. [CrossRef]

10. Trenberth, K.E.; Fasullo, J.T.; Shepherd, T.G. Attribution of climate extreme events. Nat. Clim. Chang. 2015, 5, 725-730. [CrossRef]

11. Jung, Y.; Shin, J.Y.; Ahn, H.; Heo, J.H. The Spatial and Temporal Structure of Extreme Rainfall Trends in South Korea. Water 2017, 9, 809. [CrossRef]

12. Hu, Y.; Maskey, S.; Uhlenbrook, S. Trends in temperature and rainfall extremes in the Yellow River source region, China. Clim. Chang. 2012, 110, 403-429. [CrossRef]

13. Groisman, P.Y.; Knight, R.W.; Easterling, D.R.; Karl, T.R.; Hegerl, G.C.; Razuvaev, V.N. Trends in Intense Precipitation in the Climate Record. J. Clim. 2005, 18, 1326-1350. [CrossRef]

14. Alpert, $\mathrm{P}$. The paradoxical increase of Mediterranean extreme daily rainfall in spite of decrease in total values. Geophys. Res. Lett. 2002, 29, 31-1-31-4. [CrossRef]

15. Zhao, G.; Tian, P.; Mu, X.; Jiao, J.; Wang, F.; Gao, P. Quantifying the impact of climate variability and human activities on streamflow in the middle reaches of the Yellow River basin, China. J. Hydrol. 2014, 519, 387-398. [CrossRef]

16. Ma, X.; Zuo, H.; Tian, M.; Zhang, L.; Meng, J.; Zhou, X.; Min, N.; Chang, X.; Liu, Y. Assessment of heavy metals contamination in sediments from three adjacent regions of the Yellow River using metal chemical fractions and multivariate analysis techniques. Chemosphere 2016, 144, 264-272. [CrossRef] [PubMed]

17. Yang, D.; Li, C.; Hu, H.; Lei, Z.; Yang, S.; Kusuda, T.; Koike, T.; Musiake, K. Analysis of water resources variability in the Yellow River of China during the last half century using historical data. Water Resour. Res. 2004, 40. [CrossRef]

18. Yu, L. The Huanghe (Yellow) River: Recent changes and its countermeasures. Cont. Shelf Res. 2006, 26, $2281-2298$. [CrossRef]

19. Tang, Q.; Oki, T.; Kanae, S.; Hu, H. Hydrological Cycles Change in the Yellow River Basin during the Last Half of the Twentieth Century. J. Clim. 2008, 21, 1790-1806. [CrossRef] 
20. Tang, Y.; Tang, Q.; Tian, F.; Zhang, Z.; Liu, G. Responses of natural runoff to recent climatic variations in the Yellow River basin, China. Hydrol. Earth Syst. Sci. 2013, 17, 4471-4480. [CrossRef]

21. Gao, P.; Deng, J.; Chai, X.; Mu, X.; Zhao, G.; Shao, H.; Sun, W. Dynamic sediment discharge in the Hekou-Longmen region of Yellow River and soil and water conservation implications. Sci. Total Environ. 2017, 578, 56-66. [CrossRef] [PubMed]

22. Yellow River Conservancy Commission (YRCC). Yellow River Water Resources Bulletin (2015); Yellow River Conservancy Commission of the Ministry of Water Resources: Zhengzhou, China, 2016. (In Chinese)

23. Yao, Z.; Shi, X.; Qiao, S.; Liu, Q.; Kandasamy, S.; Liu, J.; Liu, Y.; Liu, J.; Fang, X.; Gao, J.; et al. Persistent effects of the Yellow River on the Chinese marginal seas began at least $880 \mathrm{ka}$ ago. Sci. Rep.-UK 2017, 7, 2827. [CrossRef] [PubMed]

24. Liu, Q.; Cui, B. Impacts of climate change/variability on the streamflow in the Yellow River Basin, China. Ecol. Model. 2011, 222, 268-274. [CrossRef]

25. Shu, L.; Finlayson, B. Flood management on the lower Yellow River: Hydrological and geomorphological perspectives. Sediment. Geol. 1993, 85, 285-296. [CrossRef]

26. Wang, H.; Yang, Z.; Saito, Y.; Liu, J.P.; Sun, X. Interannual and seasonal variation of the Huanghe (Yellow River) water discharge over the past 50 years: Connections to impacts from ENSO events and dams. Glob. Planet. Chang. 2006, 50, 212-225. [CrossRef]

27. Gao, P.; Mu, X.M.; Wang, F.; Li, R. Changes in streamflow and sediment discharge and the response to human activities in the middle reaches of the Yellow River. Hydrol. Earth Syst. Sci. 2011, 15, 1-10. [CrossRef]

28. He, B.; Miao, C.; Shi, W. Trend, abrupt change, and periodicity of streamflow in the mainstream of Yellow River. Environ. Monit. Assess. 2013, 185, 6187-6199. [CrossRef] [PubMed]

29. Gao, Z.; Zhang, L.; Zhang, X.; Cheng, L.; Potter, N.; Cowan, T.; Cai, W. Long-term streamflow trends in the middle reaches of the Yellow River Basin: Detecting drivers of change. Hydrol. Process. 2016, 30, 1315-1329. [CrossRef]

30. Xin, Z.; Yu, X.; Li, Q.; Lu, X.X. Spatiotemporal variation in rainfall erosivity on the Chinese Loess Plateau during the period 1956-2008. Reg. Environ. Chang. 2011, 11, 149-159. [CrossRef]

31. Yan, Y.; Yang, Z.; Liu, Q. Nonlinear trend in streamflow and its response to climate change under complex ecohydrological patterns in the Yellow River Basin, China. Ecol. Model. 2013, 252, 220-227. [CrossRef]

32. Liang, K.; Liu, S.; Bai, P.; Nie, R. The Yellow River basin becomes wetter or drier? The case as indicated by mean precipitation and extremes during 1961-2012. Theor. Appl. Climatol. 2015, 119, 701-722. [CrossRef]

33. Tian, Q.; Yang, S. Regional climatic response to global warming: Trends in temperature and precipitation in the Yellow, Yangtze and Pearl River basins since the 1950s. Quat. Int. 2017, 440, 1-11. [CrossRef]

34. Kendall, M.G. A new measure of rank correlation. Biometrika 1938, 30, 81-93. [CrossRef]

35. Mann, H.B. Nonparametric tests against trend. Econometrica 1945, 13, 245-259. [CrossRef]

36. Sen, P.K. Estimates of the regression coefficient based on Kendall's tau. J. Am. Stat. Assoc. 1968, 63, 1379-1389. [CrossRef]

37. Piao, S.L.; Ciais, P.; Huang, Y.; Shen, Z.; Peng, S.; Li, J.; Zhou, L.; Liu, H.; Ma, Y.; Ding, Y.; et al. The impacts of climate change on water resources and agriculture in China. Nature 2010, 467, 43-51. [CrossRef] [PubMed]

38. Nyeko-Ogiramoi, P.; Willems, P.; Ngirane-Katashaya, G. Trend and variability in observed hydrometeorological extremes in the Lake Victoria basin. J. Hydrol. 2013, 489, 56-73. [CrossRef]

39. Ntegeka, V.; Willems, P. Trends and multidecadal oscillations in rainfall extremes, based on a more than 100-year time series of 10 min rainfall intensities at Uccle, Belgium. Water Resour. Res. 2008, 44, W07402. [CrossRef]

40. Tabari, H.; Taye, M.T.; Onyutha, C.; Willems, P. Decadal Analysis of River Flow Extremes Using Quantile-Based Approaches. Water Resour. Manag. 2017, 31, 3371-3387. [CrossRef]

41. Willems, P. Multidecadal oscillatory behaviour of rainfall extremes in Europe. Clim. Chang. 2013, 120, $931-944$. [CrossRef]

42. Kisi, O.; Ay, M. Comparison of Mann-Kendall and innovative trend method for water quality parameters of the Kizilirmak River, Turkey. J. Hydrol. 2014, 513, 362-375. [CrossRef]

43. Wu, H.; Qian, H. Innovative trend analysis of annual and seasonal rainfall and extreme values in Shaanxi, China, since the 1950s. Int. J. Climatol. 2017, 37, 2582-2592. [CrossRef]

44. Dabanlı, İ.; Şen, Z.; Yeleğen, M.Ö.; Şişman, E.; Selek, B.; Güçlü, Y.S. Trend Assessment by the Innovative-Şen Method. Water Resour. Manag. 2016, 30, 5193-5203. [CrossRef] 
45. Martínez-Austria, P.F.; Bandala, E.R.; Patiño-Gómez, C. Temperature and heat wave trends in northwest Mexico. Phys. Chem. Earth 2016, 91, 20-26. [CrossRef]

46. Onyutha, C. Identification of sub-trends from hydro-meteorological series. Stoch. Environ. Res. Risk Assess. 2016, 30, 189-205. [CrossRef]

47. Öztopal, A.; Şen, Z. Innovative Trend Methodology Applications Innovative to Precipitation Records in Turkey. Water Resour. Manag. 2017, 31, 727-737. [CrossRef]

48. Kisi, O. An innovative method for trend analysis of monthly pan evaporations. J. Hydrol. 2015, 527, 1123-1129. [CrossRef]

49. Chau, K.W.; Wu, C.L. A hybrid model coupled with singular spectrum analysis for daily rainfall prediction. J. Hydroinform. 2010, 12, 458-473. [CrossRef]

50. Wu, C.L.; Chau, K.W.; Fan, C. Prediction of rainfall time series using modular artificial neural networks coupled with data-preprocessing techniques. J. Hydrol. 2010, 389, 146-167. [CrossRef]

51. Chen, X.Y.; Chau, K.W.; Busari, A.O. A comparative study of population-based optimization algorithms for downstream river flow forecasting by a hybrid neural network model. Eng. Appl. Artif. Intell. 2015, 46, 258-268. [CrossRef]

52. Taormina, R.; Chau, K.W.; Sivakumar, B. Neural network river forecasting through baseflow separation and binary-coded swarm optimization. J. Hydrol. 2015, 529, 1788-1797. [CrossRef]

53. Gholami, V.; Chau, K.W.; Fadaee, F.; Torkaman, J.; Ghaffari, A. Modeling of groundwater level fluctuations using dendrochronology in alluvial aquifers. J. Hydrol. 2015, 529, 1060-1069. [CrossRef]

54. Wang, W.C.; Chau, K.W.; Xu, D.M.; Qiu, L.; Liu, C.C. The Annual Maximum Flood Peak Discharge Forecasting Using Hermite Projection Pursuit Regression with SSO and LS Method. Water Resour. Manag. 2017, 31, 461-477. [CrossRef]

55. Miao, C.Y.; Ni, J.R.; Borthwick, A.G.L. Recent changes of water discharge and sediment load in the Yellow River basin, China. Prog. Phys. Geogr. 2010, 34, 541-561. [CrossRef]

56. Yellow River Conservancy Commission (YRCC). Yellow River Water Resources Bulletin (2014); Yellow River Conservancy Commission of the Ministry of Water Resources: Zhengzhou, China, 2015. (In Chinese)

57. Yellow River Conservancy Commission (YRCC). Yellow River Water Resources Bulletin (2013); Yellow River Conservancy Commission of the Ministry of Water Resources: Zhengzhou, China, 2014. (In Chinese)

58. Ntegeka, V. Assessment of the Observed and Future Climate Variability and Change in Hydroclimatic and Hydrological Extremes. Ph.D. Dissertation, Katholieke Universiteit, Leuven, Belgium, 2011.

59. Baxter, S.C.; Graham, L.L. Characterization of random composites using moving-window technique. J. Eng. Mech. 2000, 126, 389-397. [CrossRef]

60. Onyutha, C.; Willems, P. Identification of the main attribute of river flow temporal variations in the Nile Basin. Hydrol. Earth Syst. Sci. Discuss. 2015, 12, 12167-12214. [CrossRef]

61. Şen, Z. Innovative Trend Analysis Methodology. J. Hydrol. Eng. 2012, 17, 1042-1046. [CrossRef]

62. Sonali, P.; Nagesh Kumar, D. Review of trend detection methods and their application to detect temperature changes in India. J. Hydrol. 2013, 476, 212-227. [CrossRef]

63. Jung, I.; Bae, D.H.; Kim, G. Recent trends of mean and extreme precipitation in Korea. Int. J. Climatol. 2011, 31, 359-370. [CrossRef]

64. Efron, B. Bootstrap methods: Another look at the jackknife. Ann. Stat. 1979, 7, 1-26. [CrossRef]

65. Efron, B. Estimation and Accuracy after Model Selection. J. Am. Stat. Assoc. 2014, 109, 991-1007. [CrossRef] [PubMed]

66. Efron, B.; Tibshirani, R.J. An Introduction to the Bootstrap; Chapman \& Hall: New York, NY, USA, 1993.

67. Davison, A.C.; Hinkley, D.V. Bootstrap Methods and Their Application; Cambridge University Press: Cambridge, UK, 1997.

68. Drought Relief Office of Shaanxi Province; Agricultural Meteorology Center of Shaanxi Province. Drought Disaster Yearbook of Shaanxi (1949-1995); Xi'an Map Press: Xi'an, China, 1999. (In Chinese) 
69. Peng, J.; Fan, Z.; Wu, D.; Zhuang, J.; Dai, F.; Chen, W.; Zhao, C. Heavy rainfall triggered loess-mudstone landslide and subsequent debris flow in Tianshui, China. Eng. Geol. 2015, 186, 79-90. [CrossRef]

70. Zhuang, J.; Peng, J.; Wang, G.; Iqbal, J.; Wang, Y.; Li, W.; Xu, Q.; Zhu, X. Prediction of rainfall-induced shallow landslides in the Loess Plateau, Yan'an, China, using the TRIGRS model. Earth Surf. Process. Landf. 2017, 42, 915-927. [CrossRef] 